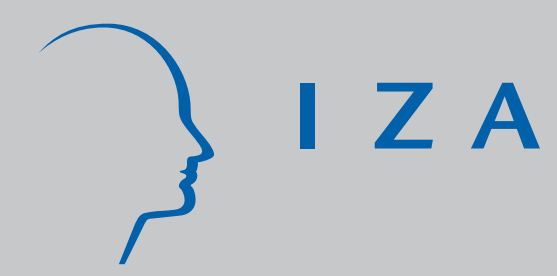

IZA DP No. 279

Product Market Integration, Wage Dispersion and Unemployment

Torben M. Andersen

April 2001 


\title{
Product Market Integration, Wage Dispersion and Unemployment
}

\author{
Torben M. Andersen \\ University of Aarhus, CEPR, EPRU and IZA, Bonn
}

Discussion Paper No. 279
April 2001

IZA

P.O. Box 7240

D-53072 Bonn

Germany

Tel.: +49-228-3894-0

Fax: +49-228-3894-210

Email: iza@iza.org

This Discussion Paper is issued within the framework of IZA's research area Internationalization of Labor Markets and European Integration. Any opinions expressed here are those of the author(s) and not those of the institute. Research disseminated by IZA may include views on policy, but the institute itself takes no institutional policy positions.

The Institute for the Study of Labor (IZA) in Bonn is a local and virtual international research center and a place of communication between science, politics and business. IZA is an independent, nonprofit limited liability company (Gesellschaft mit beschränkter Haftung) supported by the Deutsche Post AG. The center is associated with the University of Bonn and offers a stimulating research environment through its research networks, research support, and visitors and doctoral programs. IZA engages in (i) original and internationally competitive research in all fields of labor economics, (ii) development of policy concepts, and (iii) dissemination of research results and concepts to the interested public. The current research program deals with (1) mobility and flexibility of labor markets, (2) internationalization of labor markets and European integration, (3) the welfare state and labor markets, (4) labor markets in transition, (5) the future of work, (6) project evaluation and (7) general labor economics.

IZA Discussion Papers often represent preliminary work and are circulated to encourage discussion. Citation of such a paper should account for its provisional character. 
IZA Discussion Paper No. 279

April 2001

\section{ABSTRACT \\ Product Market Integration, Wage Dispersion and Unemployment}

Even when international product market integration is taking place between fairly similar countries with low labour mobility, it may have important effects for labour markets by increasing the mobility of jobs. This creates both opportunities through exports and threats from imports. Is there any reason why the benefits and costs of product market integration should be unequally distributed across different groups in the labour market? Considering integration as a gradual process lowering trade frictions it is found that there is such a bias in the sense that the gains tend to accrue to the high paid and the loses to the low paid. Product market integration may thus lead to a more inequal distribution of wages and employment, even though there are aggregate gains in terms of higher real incomes and employment.

JEL Classification: F15, J30, J50

Keywords: $\quad$ Trade frictions, wage formation, inequality and unemployment

Torben M. Andersen

Department of Economics

University of Aarhus

Building 326

DK-8000 Aarhus C

Denmark

Tel.: +458942 1609

Fax: +4586136334

Email: tandersen@econ.au.dk

* Comments from partcipants at the workshop "Globalization and the Welfare State", Kolding, the "European Summer Symposium in Labour Economics", Buch am Ammersee, and the IZA workshop "International Integration and Labour Markets" are gratefully acknowledged. Constructive and helpful comments were received from the discussants Svend Jespersen, Yves Zenou, and Pierre Picard, respectively at these two occasions. 


\section{Introduction}

How will international integration affect European labour markets? While much of the academic debate has focused on the standard arguments for gains from more free trade, less effort has been devoted to analyse the effects on unemployment and inequality. This issue is, however, receiving much attention in the public debate, and it is often asserted that international integration leads to more unemployment and wage inequality. Accordingly, international integration is often taken to be a major threat to attained levels of material well-being, and this perception is fueling an increasing opposition to international integration. It is therefore important to analyse whether and through which routes international integration may lead to more unemployment and wage dispersion both to address which initiatives can be undertaken to prevent these negative side effects from developing (labour market policy) and to discuss ways to mitigate the consequences (welfare state activities).

It is well-established that labour market performance is changing in most OECD countries. Wage dispersion is going up as is the difference in employment across both skill and geographical dimensions (see e.g. OECD (1997)). Moreover, there is a trend towards more decentralized wage formation giving a larger role for wage setting at the sectorial or firm level (see e.g. Flanagan (1999)). Since, these changes have been observed in a period in which international integration has been strengthened it is natural to conjecture that there is a relation between the two. This paper identifies potential channels through which such a relationship may arise.

International integration has two quite different dimensions. One is the integration of emerging economics into the global economy. Seen from the perspective of Western economies the primary effects induced by this form of integration arise through changes in relative factor supplies (e.g. skilled unskilled). The other dimension is the increasing regionalisation taking place at a global level, that is, more integration of e.g. European economies. These economies are fairly similar and the main effects of integration run through product market integration which strengthens competition and changes the boundaries for which goods can be traded. In this case competitiveness and comparative advantages are crucial for how integration affects labour markets.

The labour market effects of integration running via changes in relative factor supplies are captured by the Heckscher-Ohlin model. According to the Stolper-Samuleson proposition, the relative wage of unskilled in OECD countries would decline if the integration process is associated with a decline in relative prices of commodities intensive in low skilled labour. The deteri- 
orated situation for low skilled workers may more generally show up in the form of lower relative wages or a higher incidence of unemployment for low skilled workers in OECD countries ${ }^{1}$ (see e.g. Slaugther and Swagel (1997) for an introduction and references to this debate). There is an extensive empirical literature studying these issues, and the consensus is that trade can explain some but not the dominant part of the deterioration in the labour market position of low skilled workers. Changes in technology seem to be an important factor, although it can be difficult to separate out the effects of technology from those of international integration.

Even though labour markets may not be significantly affected by the integration of emerging economies, there may be effects from the ongoing integration among OECD countries. Take the case of the European economies. While there has been some increase in trade with countries outside the European area including low income countries, it is a fact that the region remains fairly closed with a consolidated trade share of about $10 \%$ of total GDP, whereas trade within the region has been rapidly increasing (see OECD(1999)). European integration has been intensified through a number of initiatives within the European Union including the Internal market and the Economic and Monetary Union. Liberalizations of capital movements have effectively created one common market for financial capital, and product markets are getting increasingly integrated. However, despite that free mobility of labour is implied by the internal market there is very little mobility of labour across European countries (OECD (1999)), and this situation is not likely to change in the near future. While there are some differences in the average skill levels among European labour markets, they are not significant among the core countries ${ }^{2}$, and still the integration process seems to be of importance for labour market performance (for empirical evidence see Andersen, Haldrup and Sørensen (2000)). Given the past unemployment record and the structural problems in European labour markets the issue of how international integration affects labour market performance is crucial.

What are the main channels through which European labour markets are affected by international integration? The point is that although people are fairly immobile, the mobility of jobs is increasing as a consequence of product market integration. Various forms of explicit or implicit costs associated with international trade of commodities imply that some types of labour/jobs are sheltered from international competition since the goods produced are non-tradeables, other groups are facing the threat from potential import

${ }^{1}$ See Davis (1998) for an interesting analysis of how this mechanism is changed if there are differences in labour market institutions.

${ }^{2}$ This is not to deny that this is a relevant issue in relation to some Southern European countries or in relation to the enlargement of the European Union. 
of products which are close substitutes (tradeables-import), while others are having the opportunity that the goods produced can be exported (tradeablesexport). International integration of product markets shrinks the part of the economy producing non-tradeables at the same time as the exposure to both the import-threat and the export-opportunity is enhanced. This may in turn affect the incentives underlying wage formation and in particular the possibilities for exerting market power. A particular important question is whether there would be a tendency for the opportunities and threats created by product market integration to be distributed differently across groups in the labour market, that is, are there systematic differences between those who will be gainers and losers?

Although there is a growing literature dealing with the effects of international integration in imperfectly competitive product and labour markets (for an introduction and references see Andersen, Haldrup and Sørensen (2000), it does not adequately address the questions raised above since the models are either partial, assume a homogeneous labour market or are cast in a (static) general equilibrium setting precluding unemployment (assuming a competitive fringe absorbing all "excess" labour). The present paper is related to this literature by assuming an imperfectly competitive labour market, and by focusing on the fact that when goods markets are getting more integrated the mobility of jobs is affected - the lower the trade frictions the more domestic and foreign firms compete over both the domestic and foreign markets. The market power of wage setters therefore depends on the extent to which product markets are internationally integrated. This mechanism is analysed in a general equilibrium model which is a version of standard (Ricardian) trade model admitting unemployment and heterogeneity in the labour market. The model can thus both address "macro questions" on how integration affects aggregate real income, employment etc., but also "micro" questions concerning effects for specific groups in the labour market, wage dispersion etc. The paper considers product market integration both from a single country perspective and from an international perspective by analysing the international equilibrium arising in a two country version of the model.

The rest of the paper is organized as follows: Section 2 develops a general equilibrium model allowing for trade frictions and heterogeneity in product and labour markets. Next the effects of product market integration in the form of lower trade friction are considered. Section 3 considers the effects from a partial or sectoral perspective to identify the main channels through which product market integration affects labour markets, and section 4 considers the international equilibrium in a two-country version of the model. Section 5 offers a few concluding comments. 


\section{The Model $^{3}$}

Consider an economy with a continuum of goods indexed by $i \in[0,1]$. Each good can in principle be produced either at home or abroad, and can be imported or exported across countries. Assume that each good has a given price $P_{i}^{*}$ (denoted in domestic currency) at the international goods market (this assumption is relaxed in section 4$)^{4}$. Trade involves various frictions in the form of explicit and implicit trade costs. Trading one unit of a commodity internationally absorbs $\kappa_{i}$ units of the good in frictions (Samuelson's iceberg costs), that is, importables cost $\left(1+\kappa_{i}\right) P_{i}^{*}$ in the domestic market and exporters get a net-price $\left(1+\kappa_{i}\right)^{-1} P_{i}^{*}$. Trade frictions are symmetric with respect to the direction of trade. International integration can now easily be captured by a reduction in $\kappa_{i}$.

\section{Production}

Assume that domestic production of a given good takes place in a representative firm possessing a production technique

$$
Y_{i}=A_{i} L_{i}
$$

where $A_{i}$ is an exogenous productivity parameter, and $L_{i}$ is the input of the production specific type of labour supplied by the representative household $i$ (see below). Notice that labour inputs are heterogenous reflecting differences in ability, education and training, and that different types of production require different types of labour ${ }^{5}$. The affiliation of specific types of labour to specific firms is a convenient short-hand to capture heterogeneity prevailing in labour markets, and effectively amounts to assuming that labour is allocated efficiently within the country according to its productivity.

Firms are competitive (with free entry) and the output price of domestically produced goods of type $\mathrm{i}$ is accordingly linked to the wage $\left(W_{i}\right)$ for the type of labour used by firm i (see below)

$$
P_{i}=A_{i}^{-1} W_{i}
$$

It follows straightforwardly that commodity i will be imported if

$$
P_{i}>\left(1+\kappa_{i}\right) P_{i}^{*}
$$

${ }^{3}$ The model structure builds on Dornbusch, Fischer and Samuelson (1977), but differs by allowing for wage differences and unemployment. See also Obstfeld and Rogoff (1996) for a textbook version of the model.

${ }^{4}$ The exchange rate is assumed fixed, i.e. nominal issues are not central to the present analysis. This corresponds to the structure among EU countries participating in the EMU.

${ }^{5}$ Differences in productivity across sectors/countries also reflect the allocation of real capital. It can also be interpreted as capturing scale effects etc. 
and exported if

$$
P_{i}<\left(1+\kappa_{i}\right)^{-1} P_{i}^{*}
$$

while it is a non-tradeable provided

$$
\left(1+\kappa_{i}\right)^{-1} P_{i}^{*} \leq P_{i} \leq\left(1+\kappa_{i}\right) P_{i}^{*}
$$

\section{Households}

The representative household type $h \in[0,1]$ supplies the specific labour type $h\left(l_{h} \leq 1\right)$ and has a utility function

$$
U_{h}=\left(\int_{0}^{1} C_{h i}^{\frac{\theta-1}{\theta}} d i\right)^{\frac{\theta}{\theta-1}}-d l_{h}, \quad \theta>1, d>0
$$

where $\mathrm{C}_{h i}$ is the consumption of commodity i by household $\mathrm{h}$, and $d$ is the disutility of labour. The implied individual labour supply curve is inelastic for a wage exceeding the reservation wage (d).

Implying that demand for commodity $i$ is

$$
C_{h i}=\left(\frac{P_{i}}{P}\right)^{-\theta} r_{h}
$$

where $r_{h}$ denotes the real income of the household $\left(=\frac{W_{h}}{P} l_{h}\right)$ and the price index is defined

$$
P=\left[\int_{0}^{1} P_{i}^{1-\theta} d i\right]^{\frac{1}{1-\theta}}
$$

The utility of household ${ }^{6} h$ can be written

$$
V_{h}=r_{h}-d l_{h}
$$

For later reference note that aggregate demand for commodity $i$ is

$$
C_{i}=\int_{0}^{1} C_{h i} d i=\left(\frac{P_{i}}{P}\right)^{-\theta} r
$$

where $\mathrm{r}\left(r \equiv \int r_{h} d h\right)$ is aggregate real income. Adopting a utilitarian welfare criterion we get that the welfare measure is

$$
V=r-d l
$$

${ }^{6}$ Notice that there is no profit income due to the assumption of constant returns to labour and free entry of firms. 


\section{Wage Setting}

The relationship between the price charged for domestically produced goods and the trade position of various goods translate directly to a relationship between the wage and the trade position. Hence, it follows straightforwardly that commodity $\mathrm{h}$ is an importable if

$$
W_{h}>W_{h}^{I} \equiv\left(1+\kappa_{h}\right) P_{h}^{*} A_{h}
$$

Setting a wage above $W_{h}^{I}$ means due to the assumption that the commodity is available at a given world market price that there is no domestic production of this commodity and thus no employment in this sector. A commodity $\mathrm{h}$ is an exportable if

$$
W_{h}<W_{h}^{E} \equiv A_{h} P_{h}^{*}\left(1+\kappa_{h}\right)^{-1}
$$

and setting a wage equal to $W_{h}^{E}$ implies an infinitely large labour demand under the small open economy assumption. Finally, the commodity $\mathrm{h}$ is a non-tradeable if

$$
W_{h}^{E} \leq W_{h} \leq W_{h}^{I}
$$

This brings out that demanding high wages $\left(W_{h}>W_{h}^{I}\right)$ implies that labour prices itself out of the market due to the possibility of importing goods, while demanding low wages $\left(W_{h}<W_{h}^{E}\right)$ expands employment possibilities through export. For intermediary levels of wages foreign trade does not directly affect market opportunities (non-tradeables).

The critical wage levels should be seen relative to both the productivity of workers, trade frictions, and the foreign prices for the relevant products. They can conveniently be characterized in terms of the value of the marginal product of labour measured in foreign output prices, i.e.

$$
\alpha_{h} \equiv A_{h} P_{h}^{*}
$$

That is, $\alpha_{h}$ is high if either the particular group of workers is very productive ( $A_{h}$ high) or the foreign price of the product is high $\left(P_{h}^{*}\right.$ high).

Figure 1 displays how the critical import and export wage depend on the value of productivity $\left(\alpha_{h}\right)$. Note that the critical import wage is proportional to the critical export wage, and therefore the two wage curves diverge when the level of the value of the marginal product of labour increases. The figure brings out the scope for wage setting created by the import threat and the export possibility, and in particular the existence of a range of wages within which the sector would be protected from international competition 
(non-tradeables). Obviously, the position of the wage curves and the range between them depend on the trade friction, and therefore product market integration can have important effects for labour markets. Two aspects are important here, namely the extent to which there is a wage rigidity preventing wages from adjusting in the downward direction under the pressure exerted by international competition and the extent to which wage earners can appropriate the rents created by trade frictions. Both of these aspects can be captured by assuming that the labour market is imperfectly competitive, and to simplify a monopoly union model can conveniently be assumed.

Figure 1: Critical Import and Export Wages

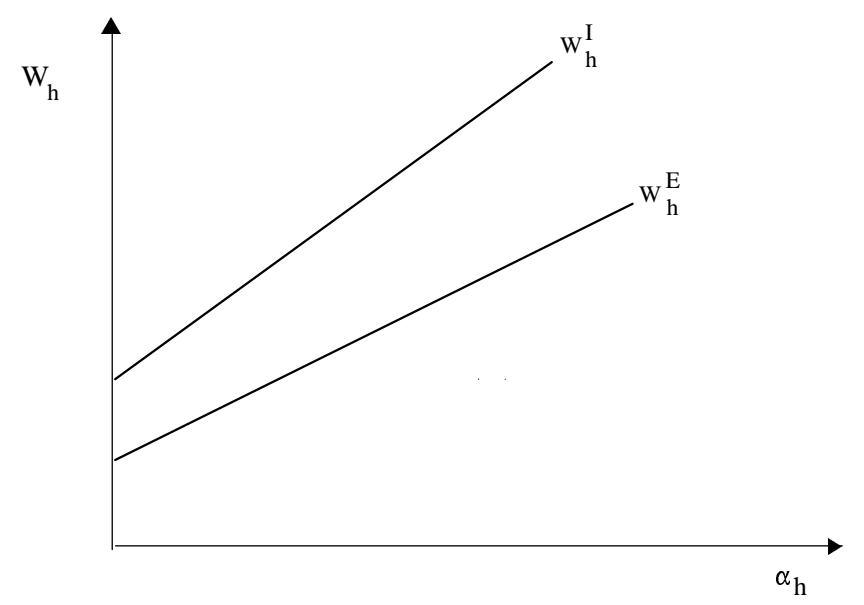

Specifically, the representative household is a monopolist in the supply of labour type $h$ aiming at maximizing the indirect utility function which can be written ${ }^{7}$

$$
l_{h}\left(\frac{W_{h}}{P}-d\right)
$$

subject to the participation constraint

$$
W_{h} \geq W^{r} \equiv d P
$$

that is, workers would not be willing to work below the reservation wage $\mathrm{W}^{r}$, which in the present setting is determined by the disutility of labour

\footnotetext{
${ }^{7}$ The fact that unions are decentralized implies that they do not perceive that wages
} have any influence on prices, i.e. the consumer price index is taken as exogenous. 
Product Market Integration, Wage Dispersion and Unemployment 8

Figure 2: Employment - Relation in Sector h

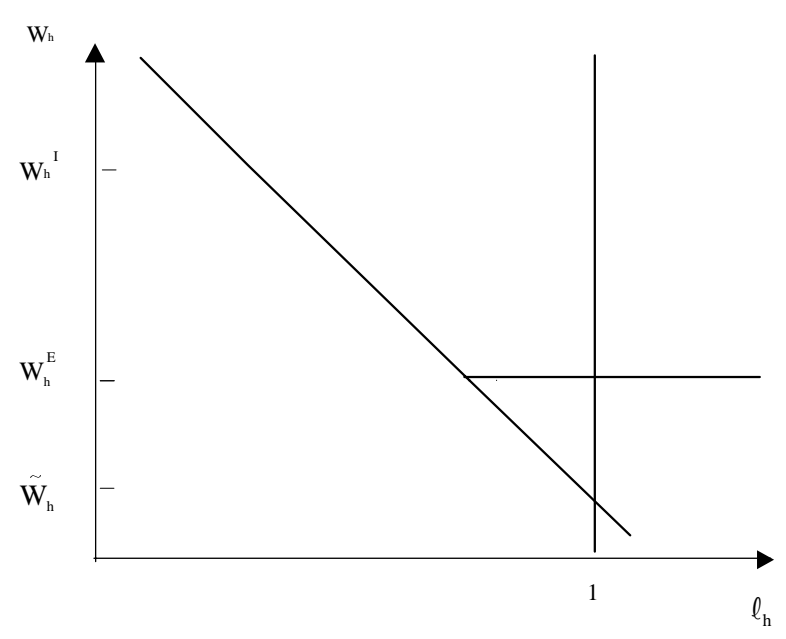

(d). In a more general setting the reservation wage would also depend on unemployment benefits ${ }^{8}$, outside market activities etc.

The implied labour demand faced by workers is such that there is no employment when demanding a wage in excess of $W_{h}^{I}$, while for a wage below $W_{h}^{E}$ there is an infinite labour demand due to the small open economy assumption of given output prices in the international product market. For intermediary wage levels the employment level can be derived from the product demand for the relevant product to read

$$
l_{h}=A_{h}^{-1}\left(\frac{A_{h}^{-1} W_{h}}{P}\right)^{-\theta} r
$$

The employment function facing union $h$ can thus be depicted ${ }^{9}$ as in Figure 2 .

The optimal wage strategy for a given union/group of workers has to take into account both the discontinuity in the labour demand relation and the participation constraint implied by the reservation wage. As a prelude to

${ }^{8}$ It would be straightforward to introduce an unemployment insurance scheme financed by lump-sum contributions by all workers in a given union. Note that aggregate demand is independent of the distribution of income, and hence such a scheme would not change anything but the wage demands of unions.

${ }^{9}$ Figure drawn for $\mathrm{W}_{h}^{E}>\widetilde{W}_{h}$. This condition need not hold, cf below. 
clarifying the optimal wage strategy it is useful to define the optimal wage for a union if we have an internal solution which is

$$
W^{m} \equiv m W^{r} \quad \text { where } m=\frac{-\theta}{1-\theta}>1
$$

This corresponds to the standard case of monopoly union under a right to manage structure, where the optimal wage is given as a mark-up on the reservation wage. The mark-up is decreasing in the absolute value of the labour demand elasticity. The wage $W^{m}$ is the wage unions will aim at up to the constraint set by the import threat and the export possibility.

Let $\widetilde{W}_{h}$ denote the wage ensuring full employment for labour type $h$ if the commodity is a non-tradeable. The following analysis is made under the assumption that $\widetilde{W}_{h}<W^{r}$ for at least one sector (the one with the lowest value of the marginal product of labour), that is, the minimum wage is a binding constraint preventing full employment. In the absence of this assumption the outcome would trivially be one of full employment for low productivity workers. This assumption thus ensures that we can restrict attention to cases where unemployment may arise.

We have for $\kappa_{h} \geq \kappa^{*}$ that the optimal wage is given as (for the definition of the critical values of $\alpha$ and $\kappa$ see appendix A)

$$
W_{h}=\left\{\begin{array}{c}
W^{r} \text { for } \alpha_{h}<\alpha_{h}^{I} \\
W_{h}^{I} \text { for } \alpha_{h}^{I} \leq \alpha_{h}<\alpha_{h}^{N T} \\
W^{m} \text { for } \alpha_{h}^{N T} \leq \alpha_{h}<\alpha_{h}^{N E} \\
W_{h}^{E} \text { for } \alpha_{h} \geq \alpha_{h}^{N E}
\end{array}\right.
$$

While for $\kappa_{h}<\kappa^{*}$ we have

$$
W_{h}=\left\{\begin{array}{c}
W^{r} \text { for } \alpha_{h}<\alpha_{h}^{I} \\
W_{h}^{I} \text { for } \alpha_{h}^{I} \leq \alpha_{h}<\alpha_{h}^{I E} \\
W_{h}^{E} \text { for } \alpha_{h} \geq \alpha_{h}^{I E}
\end{array}\right.
$$

Figure 3 and 4 illustrate for the two cases how the wage depends on the value of the marginal product of labour evaluated at foreign producer prices, $\alpha_{h}$. Note that the downward jump in wages arises when the workers prefer the lower "export" wage with full employment to the higher union wage implying less employment. This feature depends critically on the small open economy assumption made (see below for the two country case). If trade frictions are sufficiently low $\left(\kappa_{h}<\kappa^{*}\right)$ there is no possibility of maintaining a non-tradeable sector. 
Figure 3: Wage Functions $\kappa_{h} \geq \kappa^{*}$

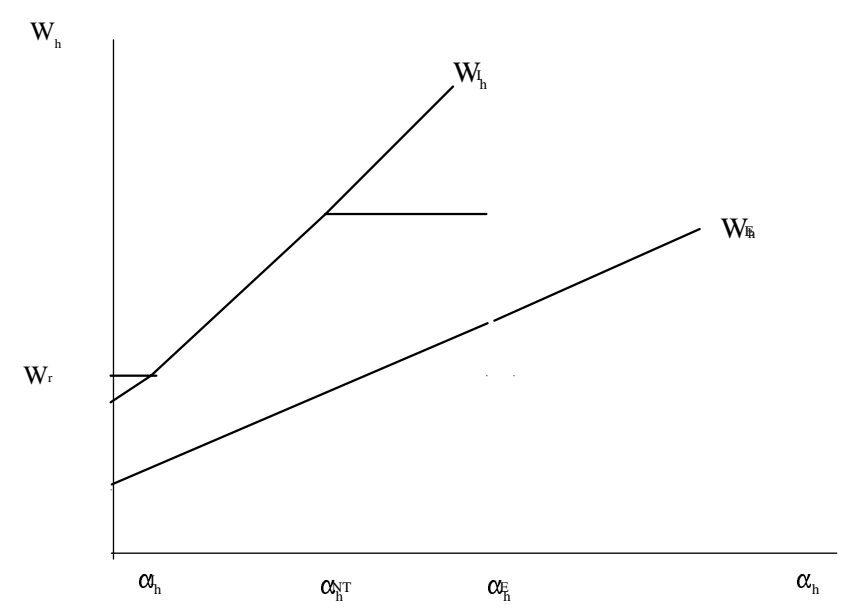

One immediate and crucial implication is that wage moderation to contest the import threat is relevant for sectors with a low $\alpha$-value. Wage moderation to ensure export is not relevant here since the needed wage reduction would imply a wage below the reservation wage. Oppositely, for sectors with a high $\alpha$-value. Hence, even though exporting calls for relative low wages for a given productivity level, we find that sectors actually exporting are sectors with a high value of the marginal product of labour and thus being the "high" wage sectors, and oppositely for the import threat. The union wage can arise only in the sectors protected from international competition due to sufficiently high trade frictions. These statements are made conditional on a given level of sector specific trade frictions, and comparing across sectors with different trade frictions we have that sectors with high trade frictions tend other things being equal to be non-tradeables, while those with lower trade frictions tend to be tradeables.

To consider the situation various sectors can be in, take the case where $\kappa_{h} \geq \kappa^{*}$. The reasoning can easily be modified to capture the case where $\kappa_{h}<\kappa^{*}$. For sectors $\mathrm{i} \in I$, where $I=\left\{\alpha_{i} \mid \alpha_{i}<\alpha_{h}^{I}\right\}$, we have that domestic production is not profitable at the reservation wage, and these commodities are imported, and therefore there is no employment. Unemployment is caused by the reservation wage of workers, i.e. a classical type of unemployment. For sectors i $\in C I$, where $C I=\left\{\alpha_{i} \mid \alpha^{I}<\alpha_{i}<\alpha_{h}^{N T}\right\}$, production is contested by imports, this implies that the threat of imports is dictating wages. As a consequence wage setters have no market power but are enforced to quote a wage level preventing import, employment is determined by domestic demand 
Figure 4: Wage Functions $\kappa_{h}<\kappa^{*}$

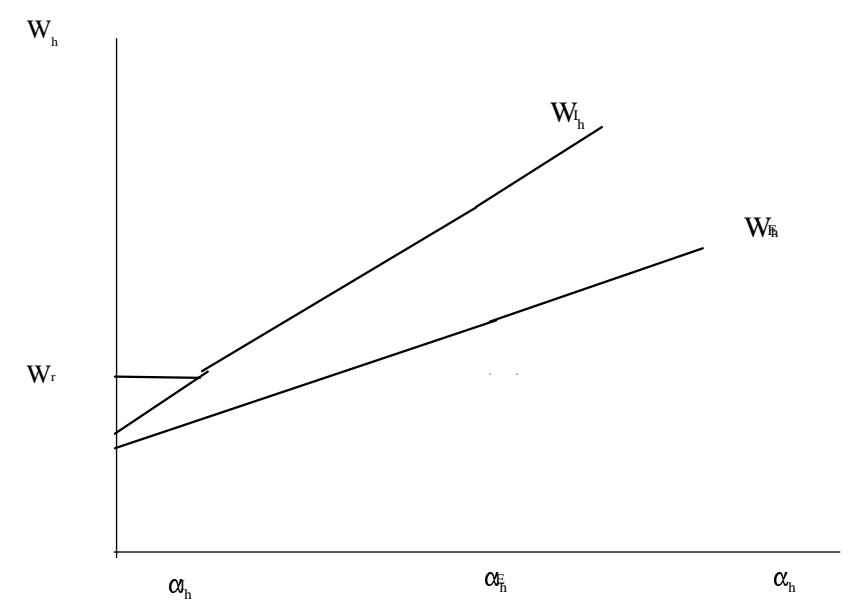

for the type of commodities produced. Unemployment arises when demand falls short of capacity output, i.e. a kind of Keynesian type of unemployment prevails. For these sectors the wage which can be demanded is proportional to $\alpha_{i}$. For sectors $\mathrm{i} \in N T$, where $N T=\left\{\alpha_{i} \mid \alpha_{h}^{N T}<\alpha_{i}<\alpha_{h}^{E}\right\}$, we have that wage setters can demand the "union wage" since production is not threathened by international competition due to the trade frictions, i.e. the commodity is a non-tradeable. The market power of wage setters is thus directly linked to the protection from foreign competition induced by trade frictions. In this case, there is unemployment which is increasing in the market power of unions (Classical type of unemployment) and decreasing in the demand for this type of commodities (Keynesian type of unemployment). Finally, for sectors $\mathrm{i} \in E$, where $E=\left\{\alpha_{i} \mid \alpha_{i}>\alpha_{h}^{E}\right\}$ there is a possibility of exporting commodities which implies that there is full employment in these sectors under the assumption that the foreign output price is exogenous. The wage is proportional to productivity.

\section{Sectorial Effects}

International integration of product markets is modelled as a reduction in the explicit and implicit trade costs. We first consider the partial or sectorial implications as a prelude to the subsequent analysis of the general equilibrium effects (micro vs macro).

Consider a drop in the trade friction in sector $\mathrm{h}\left(\kappa_{h}\right)$. Lower trade frictions 
have direct effects on wage formation. The wage in sectors contested by imports decreases, i.e.

$$
\frac{\partial W_{h}^{C I}}{\partial \kappa_{h}}>0 \quad \forall h \in C I
$$

which in terms of figure 3 corresponds to a downward shift of the curve displaying the critical import wage. Lower trade friction increases the critical export wage, i.e

$$
\frac{\partial W_{h}^{E}}{\partial \kappa_{h}}<0 \quad \forall h \in E
$$

which in figure 3 corresponds to an upward shift in the curve displaying the critical export wage. Consequently, the scope for appropriating the union wage is reduced and since neither the optimal union wage nor the reservation wage of workers are affected

$$
\frac{\partial W^{m}}{\partial \kappa_{h}}=\frac{\partial W^{r}}{\partial \kappa_{h}}=0
$$

it follows that lower trade costs imply that there is a larger set of commodities for which domestic production is not profitable, i.e. the number of I-sectors increases,

$$
\frac{\partial \alpha_{h}^{I}}{\partial \kappa_{h}}<0
$$

The intuition is simply that the lower trade frictions make it profitable for more foreign firms to penetrate into the domestic market, and the reservation wage puts a limit on how much the domestic wage can be lowered to maintain domestic production.

Lower trade frictions also increase the fraction of sectors contested by imports

$$
\frac{\partial\left(\alpha_{h}^{N T}-\alpha_{h}^{I}\right)}{\partial \kappa_{h}}<0
$$

and increase the fraction of sectors which benefit from gaining an export possibility, i.e.

$$
\frac{\partial \alpha_{h}^{E}}{\partial \kappa_{h}}>0
$$


Product market integration will thus create winners and losers in the domestic labour market. Those workers engaged in the production of commodities facing the threat of imports will face lower wages or eventually be priced out of the market, and more workers will find themselves in this situation. On the other hand workers engaged in production with export possibilities get higher wages and the share of workers for which this is relevant goes up. An implication of both of these trends is that the non-tradeable sector shrinks which can be interpreted as a decline in the effective market power of unions. In terms of the unemployment consequences we find that the type of unemployment caused by unions exerting their market power is reduced, in this way international product market integration works as an implicit structural labour market reform. However, the type of unemployment caused by the reservation wage for workers increases, and in this way product market integration may worsen structural problems in the labour market. A further implication of lower trade frictions is that wages in more sectors come to follow productivity more closely ${ }^{10}$. Finally, the labour market changes found here are associated with increases in trade volumes (import and export both increases), that is, product market integration in the form of lower trade frictions not only affects relative price but also volumes.

It is often debated whether the effects of international integration are similar to the effects of productivity changes. An increase in productivity will unambiguously lead to higher wages for both workers in the sectors contested by imports and the exportable sectors. Moreover, it will change the whole distribution of the value of the marginal product of labour to the right. That is, fewer sectors will be priced out by imports, and more sectors will have an export potential. This brings out that product market integration and productivity changes can have different effects.

\section{Symmetric Two-country Equilibrium}

The preceding analysis has taken a single country perspective, i.e. all foreign variables have been taken to be exogenous. Although a convenient simplifying assumption it is critical since international integration of product markets is a multilateral rather than a unilateral process. The preceding results may thus be misleading since they rely on foreign variables being unaffected by international integration. Hence, this section turns to an analysis of how the two-country equilibrium is affected by reduced trade frictions. To simplify it

\footnotetext{
${ }^{10}$ The present analysis assumes decentralized wage setting. This implication indicates that the costs of maintaining centralized wage setting with egalitarian wage policies increase when product markets integrate.
} 
is assumed that the two countries are completely symmetric (for productivity this applies to the distribution of productivity, cf below) and that they both have the structure outlined above for a single country. All foreign variables are denoted by $a^{*}$.

The preceding analysis revealed that the sectors may be affected differently due to the heterogeneity among them including different trade frictions for different types of commodities. This suggests that it is difficult to obtain unambiguous effects. However, it is possible to obtain some insights concerning aggregate effects under the simplifying assumption that $\kappa_{h}=\kappa$ $\forall h$.

Define the relative productivity of domestic labour relative to foreign labour in producing commodity i, i.e.

$$
a_{i} \equiv \frac{A_{i}}{A_{i}^{*}}
$$

Productivity is distributed identically in the two countries, and the sectors are indexed in such a way that $a_{i}$ is increasing in $i$, that is, for low values of $i$ the foreign country has a comparative advantage, and for high values of $i$ the home country has a comparative advantage. The comparative advantage variable $a_{i}$ is symmetrically distributed with a density function ${ }^{11} \mathrm{~g}(\mathrm{i})$, where $\mathrm{i} \in\left[\lambda^{-1}, \lambda\right], \lambda<1 .{ }^{12}$ This implies that $\mathrm{a}_{i}=1$ for $\mathrm{i}=1 / 2$, that is, for half the sectors the domestic economy has a comparative advantage relative to the foreign country and vice versa. Note that it is an implication that the average skill levels are the same in the two countries, and similar trade frictions in all sectors rule out that some low productivity sectors can be protected by high trade frictions so as to maintain a status as non-tradeables.

It can be shown (see Appendix B) that there exists an equilibrium with specialized production of traded goods ${ }^{13}$, and in which the position of each sector is determined as follows:

Case I: $\mathrm{a}_{i}<\frac{1}{(1+\kappa) m}$, the commodity is imported in home and exported from foreign, $\mathrm{W}_{i}^{*}=A_{i}^{*} P_{i}^{*}>W^{m}$

${ }^{11}$ It is assumed that $g(i)<g *$, that is, the distribution of comparative advantage does not have much mass at a single level.

${ }^{12}$ Assume that $A_{i}$ is uniformly distributed over the inverval $[1-x, 1+x]$ and similarly for $A_{i}^{*}$. Hence $\frac{A_{i}}{A_{i}^{*}}$ is distributed over the interval $\left[\frac{1-x}{1+x}, \frac{1+x}{1-x}\right]$, with a density function with the property that $\mathrm{f}\left(\frac{1}{y}\right)=f(y)$.

${ }^{13}$ Given the exogenous produtivity it follows that production will be specialized for traded goods unless production capacity does not allow a firm to supply the product market in both countries. 
Case II: $\frac{1}{(1+\kappa) m} \leq \mathrm{a}_{i}<\frac{1}{(1+\kappa)}$, the commodity is a contestable import at home, and a non-tradeable at foreign, $\mathrm{W}_{i}=a_{i}^{-1}(1+\kappa) W^{m}, W_{i}^{*}=W^{m}$

Case III: $\frac{1}{(1+\kappa)} \leq \mathrm{a}_{i} \leq(1+\kappa)$, the commodity is a non-tradeable in both countries, $\mathrm{W}_{i}=W_{i}^{*}=W^{m}$.

Case IV: $(1+\kappa)<\mathrm{a}_{i} \leq(1+\kappa) m$, the commodity is a non-tradeable at home, and a contestable import abroad, $\mathrm{W}_{i}=W^{m}, W_{i}^{*}=a_{i}(1+\kappa) W^{m}$.

Case V: $(1+\kappa) m<\mathrm{a}_{i}$, the commodity is exported from home and imported at foreign, $\mathrm{W}_{i}=a_{i} P_{i}>W^{m}$.

Note that the consumer price index is normalized to unity, implying that all wages can be interpreted as real wages.

Relative productivity determines the situation of a given sector. Sectors with relatively low productivity (case I) are unable to compete on competitive terms and these commodities are not produced in the home country but imported. Some sectors (case II) can remain competitive but face wage competition leading to lower wages. Sectors with intermediary levels of relative productivity are protected by the trade frictions in the sense that the commodities are not traded, and neither the threat of import nor the possibilities of exporting have any direct effects on the market situation, and the workers in these sectors exert market power (case III and IV). Finally, the high productive sectors (Case V) have an export possibility which leads to higher wages and employment.

A reduction in trade frictions obviously reduces the non-tradeable sectors, since some of the previously non-tradeable sectors now face competition from imports while the possibility of exporting becomes relevant for others. Clearly, workers in exporting sectors stand to win and workers in importing sectors (including contestable imports) stand to loose. Moreover, the interval of relative productivity supporting contestable import is increasing in trade costs, that is, some sectors shift from being contestable imports to being imports, but even more shift from being non-tradeables to becoming contestable import sectors. Figure 5 illustrates how a reduction of trade frictions affects the labour market. ${ }^{14}$

As already suggested by the sectorial analysis there seems to be a trade-off between the effects of lower trade frictions on aggregate material well-being and distribution. This can be substantiated in the following way.

\footnotetext{
${ }^{14}$ Note that the discontinuity present in figure 3 and 4 disappears here, since it relied on the small open economy assumption made in the one-country analysis.
} 
Lower trade costs have aggregate welfare effects in terms of increasing aggregate real income(see appendix B for details), i.e.

$$
\frac{\partial r}{\partial \kappa}<0
$$

and aggregate employment goes up, since it is decreasing in trade frictions (see appendix B)

$$
\frac{\partial l}{\partial \kappa}<0
$$

Despite the fact that these two changes have opposite effects on (utilitarian) welfare it follows that aggregate welfare improves. The reason is the inefficiency implied by the market power of workers implying that aggregate wages are larger than the reservation wage (disutility of work) and therefore the income effect dominates the disutility effect of larger employment ${ }^{15}$.

Lower trade frictions also have distributional consequence since it leads to more wage dispersion. This is quite obvious from figure 5, the low paid get lower wages and the high paid higher wages. This shows that the gains and losses from international integration are unequally distributed. The point is that those who initially have high wages have this because they have (relative) high productivity, and hence they would face new opportunities when market frictions are lowered. Oppositely, those having low wages initially are the low (relative) productive groups and they would face the threat from import when trade frictions are reduced.

Formally we have that if wage dispersion is measured by the variance of wages in different sectors/firms i.e.

$$
\Omega=\int\left(W_{i}-E W\right)^{2} g(i) d i
$$

where EW is the mean value of wages, then there is an unambiguous decrease in wage dispersion if trade frictions increase (see appendix $\mathrm{C}$ for proof), i.e.

$$
\frac{\partial \Omega}{\partial \kappa}<0
$$

$>$ From a political economy point of view it may be of interest to consider the number of gainers and losers. All workers for whom $((1+\kappa) m)^{-1} a_{i} \leq$ $(1+\kappa)^{-1}$ will loose and those for whom $a_{i}>(1+\kappa)^{-1}$ will gain. Since the

${ }^{15}$ It follows that $\frac{\partial(r-d l)}{\partial \kappa}>0$ if $\frac{\partial r}{\partial \kappa}>d \frac{\partial l}{\partial \kappa}$ which is the case since average wages exceed the competitive wage on average. 
Figure 5: Wage Functions - Symmetric Equilibrium

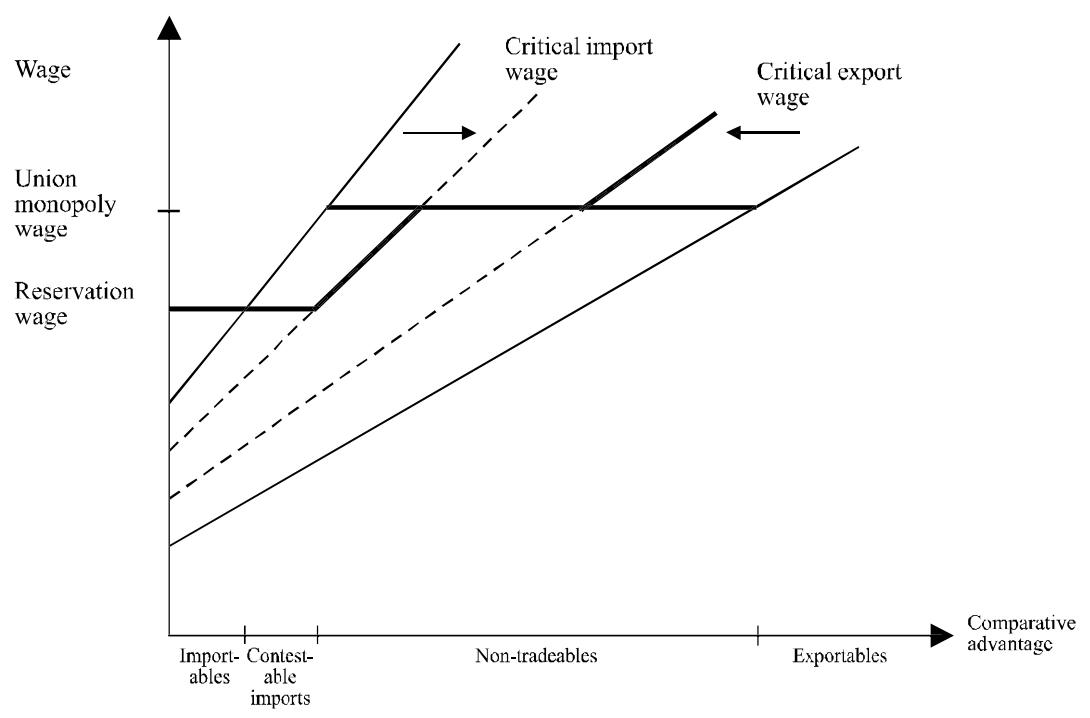

former group is decreasing and the latter increasing in $\kappa$, this suggests that the support for integration is increasing in $\kappa$.

Another interesting issue is how further integration affects the "protected" or non-tradeable group exerting monopoly power. Intuitively, one might expect that this group would be opposed integration. This need not, however, be the case. To see this note that for given trade $\operatorname{costs} \kappa$ we have that the sectors producing non-tradeables obtain the "union wage", i.e. $\mathrm{w}=\mathrm{w}^{m}$ have a relative productivity given by $a_{h} \in\left[\frac{1}{1+\kappa},(1+\kappa) m\right]$. Some workers benefit from this situation since the trade costs protect them from international competition and this allows them to demand a non-competitive wage. However, some non-tradeable sectors may be disadvantaged since they could benefit from lower trade costs yielding them better market possibilities via exports. Actually we have in the limit of no trade costs $(\kappa \rightarrow 0$ ) that $\mathrm{w}=\mathrm{w}^{m}$ for $a_{h}=w^{m}$. It follows that the group protected by trade cost is found in those sectors for which $\frac{1}{1+\kappa}<a_{h}<w^{m}$, while the sectors for which $\mathrm{w}^{m}<a_{h}<(1+\kappa) m$ are disadvantaged by this. Notice that $\left(\mathrm{w}^{m}-\frac{1}{1+\kappa}\right)<\left((1+\kappa) m-w^{m}\right)$, that is, the group benefitting from the protection offered by trade frictions is smaller than the group being harmed by such frictions.

As in the partial model, it is worth stressing that these consequences are associated with increases in trade flows. - Lower trade frictions will simultaneously cause changes in the labour market and increase in trade 
flows.

Consider finally the effects of productivity changes relative to the effects of changes in trade frictions. General productivity changes will not affect anything in the symmetric equilibrium for the obvious reason that relative productivity or comparative advantage is unchanged. A change in (relative) productivity across groups in the form of more dispersion in productivity will have effects similar to lower trade frictions in the sense that those in the low end will be priced out of the market and those in the high end will be in a better position. There is however one difference between productivity and trade frictions which have interesting testable implications, namely, that a wider dispersion in productivity will leave the non-tradeable sector unaffected, while lower trade frictions make it shrink.

\section{Conclusion}

In the public debate concerning the labour market effects of international integration one often encounters three quite different viewpoints. Some argue that this process will lead to more heterogeneity with larger disparities between winners and losers. Some argue that new opportunities are created which will lead to higher wages and employment. Finally, some are concerned that structural labour market problems will imply that domestic labour may be priced out of the market.

The present analysis shows that the effects of international integration may be quite different for different segments of the labour market, and this implies that there is some truth in all three arguments, although none of them fully capture all the effects of international integration. Product market integration is a threat to those who will face the competition of importers ${ }^{16}$ while an opportunity for those who obtain an export possibility. Since the former tends to be concentrated in low wage jobs and the latter in high wage jobs, the process may entail more wage dispersion. Structural problems have two dimensions, namely the market power of wage setters and the reservation wage of workers. The market power of workers is reduced due to product market integration and therefore the structural problems arising due to market power in wage setting will be reduced, that is, product market integration may work as an implicit labour market reform. On the other hand the problems caused by the reservation wage increases since fewer may be able to find employment for which the offered wage exceeds the reservation wage.

${ }^{16}$ Borjas and Ramey (1985) find evidence supporting that the import threat may play a crucial role for the rent in particular low skilled workers can appropriate. 
While aggregate unemployment goes down its distribution changes with a larger burden of unemployment falling on the "low wage" - group and less unemployment among the intermediary group, that is, integration of product markets is associated with more inequality in the distribution of employment and wages.

Productivity has been assumed constant in the present analysis. The productivity differences which are the source of comparative advantage in the model may arise due to differences in human capital, learning by doing, technical progress and so on. Hence, even though not endogenized the present analysis may be interpreted in the lines of modern international trade theory stressing scale effects, product differentiation and innovations as important sources for international trade.

The finding that integration may increase unemployment for some groups can be criticized for relying on the exogenous productivity and no mobility of labour, precluding workers from moving to another sector with better employment prospects. However, the pressure for mobility created by lower trade friction is in the upward direction, that is, workers with low comparative advantage have to move up in the distribution to be employable. For high productivity workers lower trade frictions don't create any incentive to be mobile. Hence, it is not clear that it is realistic to perceive that mobility of labour would change the qualitative results of this analysis in any significant way. In a long run time perspective one may even argue that the increased wage inequality may pose a problem since it in combination with capital market imperfections may reduce the possibilities for off-springs of low paid workers in getting a job or education.

The present analysis suggests that an active labour market policy directed towards education and training of the work force to minimize productivity differences is a feasible way by which to ensure an equal wage distribution in the medium to the long run. To the extent that equality in wages across sectors/skill etc. has been maintained under the shield provided by trade frictions it stands to deteriorate in the process of international integration.

While an active labour market policy may go some way to minimize the adverse distributional consequences of international integration it is unlikely to be sufficient. Two important effects arise, since the fraction of workers being unemployed due to the reservation wage increases and since the wage dispersion goes up. Hence, countries pursuing egalitarian policies face the challenge of how to maintain and extend social policies in a more international integrated world in which it may be more difficult to use taxes to finance social security (see e.g. the discussion in Rodrik (1997) and Agell (2000)). 


\section{Appendix A: Optimal Wage Setting}

This appendix derives the optimal wage strategy of a single union. Note for a start that it follows from the definitions that $\mathrm{W}^{r}<W^{m}$ and $\mathrm{W}_{h}^{I}>W_{h}^{E}$ Define $\alpha_{h} \equiv A_{h} P_{h}^{*}$.

We need to define the following critical levels for $\alpha_{h}$ :

$\alpha_{h}^{I}$ is defined by the $\alpha_{h}$ for which $\mathrm{W}_{h}^{I}=W^{r}$,i.e. $\alpha_{h}^{I} \equiv d P(1+\kappa)^{-1}$.

$\alpha_{h}^{N T}$ is defined by the $\alpha_{h}$ for which $\mathrm{W}_{h}^{I}=W^{m}$,i.e. $\alpha_{h}^{I} \equiv m d P(1+\kappa)^{-1}$.

$\alpha_{h}^{I E}$ is defined by the $\alpha_{h}>\alpha_{h}^{I}$ for which the union utility is the same under the higher $\mathrm{W}_{h}^{I}$ implying less than full employment as compared to the lower $W_{h}^{E}$, implying full employment, i.e.

$$
\left[\frac{W_{h}^{E}}{P}-d\right]=l_{h}\left(W_{h}^{I}\right)\left[\frac{W_{h}^{I}}{P}-d\right]
$$

or implying that $\alpha_{h}^{I E}$ is defined from

$$
\left[\frac{\alpha_{h}^{I E}(1+\kappa)^{-1}}{P}-d\right]=l_{h}\left(\alpha_{h}^{I E}(1+\kappa)^{-1}\right)\left[\frac{\alpha_{h}^{I E}(1+\kappa)^{-1}}{P}-d\right]
$$

Clearly $\alpha_{h}^{I E}$ is increasing in $\kappa$.

$\alpha_{h}^{N E}$ is defined by the $\alpha_{h}>\alpha_{h}^{I}$ for which the union utility is the same under the higher $\mathrm{W}^{m}$ implying less than full employment as compared to the lower $W_{h}^{E}$, implying full employment, i.e.

$$
\left[\frac{W_{h}^{E}}{P}-d\right]=l_{h}\left(W^{m}\right)\left[\frac{W^{m}}{P}-d\right]
$$

or implying that $\alpha_{h}^{N E}$ is defined from

$$
\left[\frac{\alpha_{h}^{N E}(1+\kappa)^{-1}}{P}-d\right]=l_{h}\left(W^{m}\right)\left[\frac{W^{m}}{P}-d\right]
$$

Clearly $\alpha_{h}^{N E}$ is increasing in $\kappa$, and larger than $\alpha_{h}^{I E}$, since $\mathrm{W}^{m}$ maximizes the right hand side of this expression.

For $\alpha_{h} \leq \alpha_{h}^{I}$ we have that $\mathrm{W}^{r}>W_{h}^{I}$, that is, the attainable market wage falls short of the reservation wage, and the optimal wage is $W_{h}=W^{r}$.

For $\alpha_{h}^{I}<\alpha_{h} \leq \min \left\{\alpha_{h}^{N T}, \alpha_{h}^{I E}\right\}$ the optimal wage is $\mathrm{W}_{h}=W_{h}^{I}>W^{r}$ the reason is that the union wage is not feasible and charging the export wage would yield less utility.

For $\alpha_{h}^{I E}<\alpha_{h}^{N T}$ we have that the optimal wage is $\mathrm{W}_{h}=W_{h}^{E}$ for $\alpha_{h}>$ $\alpha_{h}^{I E}$.

For $\alpha_{h}^{I E}>\alpha_{h}^{N T}$ we have that the optimal wage is $\mathrm{W}_{h}=W^{m}$ for $\alpha_{h}^{N T}<$ $\alpha_{h}<\alpha_{h}^{N E}$ and the wage $\mathrm{W}_{h}=W_{h}^{E}$ for $\alpha_{h}^{N E}<\alpha_{h}$. 
Note that $\alpha_{h}^{I E}$ is increasing in $\kappa$ and has a finite value for $\kappa=0$, and $\alpha_{h}^{N T}$ is decreasing in $\kappa$ and goes to infinity for $\kappa$ going to zero. Hence, there exists a $\kappa^{*}$ such that $\alpha_{h}^{I E}<\alpha_{h}^{N T}$ for $\kappa<\kappa^{*}$ and $\alpha_{h}^{I E}>\alpha_{h}^{N T}$ for $\kappa>\kappa^{*}$.

\section{Appendix B: Symmetric Two-country Equilibrium}

This section derives the condition clarifying the role of various sectors provided that an equilibrium exists to the symmetric two-country version of the model. Given the symmetry we have that $\mathrm{r}=\mathrm{r}^{*}$, and $\mathrm{P}=\mathrm{P}^{*}=1$, where the last equality is a convenient normalisation.

(I) Goods non-tradeables in both countries.

A commodity is a non-tradeable at home if

$$
(1+\kappa)^{-1} P_{i}^{*}<P_{i}<(1+\kappa) P_{i}^{*}
$$

and abroad if

$$
(1+\kappa)^{-1} P_{i}<P_{i}^{*}<(1+\kappa) P_{i}
$$

For non-tradeables goods unions demand the union wage, and the price is therefore given as

$$
\begin{aligned}
& P_{i}=A_{i}^{-1} W^{m} \\
& P_{i}^{*}=A_{i}^{*-1} W^{m}
\end{aligned}
$$

Combining these we get

$$
\begin{aligned}
& (1+\kappa)^{-1} A_{i}^{*-1} W^{m}<A_{i}^{-1} W^{m}<(1+\kappa) A_{i}^{*-1} W^{m} \\
& (1+\kappa)^{-1} A_{i}^{-1} W^{m}<A_{i}^{*-1} W^{m}<(1+\kappa) A_{i}^{-1} W^{m}
\end{aligned}
$$

or

$$
\begin{aligned}
& (1+\kappa)^{-1}<\frac{A_{i}^{*}}{A_{i}}<(1+\kappa) \\
& (1+\kappa)^{-1}<\frac{A_{i}}{A_{i}^{*}}<(1+\kappa)
\end{aligned}
$$

Hence, $\forall i:(1+\kappa)^{-1}<a_{i}<(1+\kappa)$ we have that the commodity is a non-tradeable both at home and at foreign.

(II) Goods contestable imports at home, and non-tradeables at foreign. 
Product Market Integration, Wage Dispersion and Unemployment 22

The foreign price is

$$
P_{i}^{*}=A_{i}^{*-1} W^{m}
$$

and therefore the domestic wage is

$$
W_{i}=(1+\kappa) a_{i} W^{m}
$$

Where

$$
W_{i}<W^{m} \text { for } \mathrm{a}_{i}<\frac{1}{1+\kappa}
$$

and

$$
W_{i} \geq W^{r} \quad \text { for } \quad \mathrm{a}_{i} \geq \frac{1}{(1+\kappa) m}
$$

Hence, this case prevails for

$$
\frac{1}{(1+\kappa) m} \leq \mathrm{a}_{i}<\frac{1}{1+\kappa}
$$

(III) Goods contestable imports at foreign, and non-tradeables at home If the good is a non-tradeable at home, domestic unions demand the union wage and the domestic price becomes

$$
P_{i}=A_{i}^{-1} W^{m}
$$

If the commodity is a contestable import at foreign it follows that the foreign wage is

$$
W_{i}^{*}=(1+\kappa) a_{i}^{-1} W^{m}
$$

where

$$
W_{i}^{*}<W^{m} \text { for } \mathrm{a}_{i}>1+\kappa
$$

and

$$
W_{i}^{*} \geq W^{r} \text { for } \mathrm{a}_{i} \leq(1+\kappa) m .
$$

Hence, this case prevails for

$$
1+\kappa \leq \mathrm{a}_{i}<(1+\kappa) m .
$$

(IV) Goods importable at home, exportable at foreign. 
Product Market Integration, Wage Dispersion and Unemployment 23

We next have to prove that goods for which

$$
a_{i}<\frac{1}{(1+\kappa) m}
$$

are imported at home, and export from foreign. It follows from the previous analysis that the goods must be a tradeable. Hence we therefore only have to prove the direction of trade is from foreign to home.

Assume that trade runs from home to foreign. The lowest price at which domestic producers can offer the product is

$$
P_{i}^{\text {low }}=A_{i}^{-1} d
$$

which clearly exceeds to lowest price at which the commodity can be produced at foreign,

$$
P_{i}^{* l o w}=A_{i}^{*-1} d
$$

the foreign producers clearly have a competitive lead.

Finally, we need to prove that foreign workers can get the competitive wage

$$
W_{i}^{*}=A_{i}^{*} P_{i}^{*} \geq W^{m} .
$$

This is feasible when the foreign price is in the non-empty interval

$$
A_{i}^{*} m d<P_{i}^{*}<A_{i}^{-1} d(1+\kappa)
$$

where the price $P_{i}^{*}$ is determined from

$$
A_{i}^{*}=\left(P_{i}^{*}\right)^{-\theta}\left(1+(1+\kappa)^{-\theta}\right) r
$$

Note, that is assumed that

$$
\frac{1}{\lambda}<\frac{1}{(1+\kappa) m}
$$

(V) Goods exportable at home, importable at foreign

Next, we have to prove that goods for which

$$
a_{i}>(1+\kappa) m
$$

are imported at home, and export from foreign. It follows from the previous analysis that the goods must be a tradeable. Hence we therefore only have to prove the direction of trade is from foreign to home. 
Product Market Integration, Wage Dispersion and Unemployment 24

Assume that trade runs from home to foreign. The lowest price at which foreign producers can offer the product is

$$
P_{i}^{* l o w}=A_{i}^{*-1} d
$$

which clearly exceeds to lowest price at which the commodity can be produced at home,

$$
P_{i}^{\text {low }}=A_{i}^{-1} d
$$

the foreign producers clearly have a competitive lead.

Finally, we need to prove that foreign workers can get the competitive wage

$$
W_{i}^{*}=A_{i}^{*} P_{i}^{*} \geq W^{m} .
$$

This is feasible when the foreign price is in the non-empty interval

$$
A_{i} m d<P_{i}<A_{i}^{*-1} d(1+\kappa)
$$

where the price $P_{i}$ is determined from

$$
A_{i}=\left(P_{i}\right)^{-\theta}\left(1+(1+\kappa)^{-\theta}\right) r
$$

It is assumed that

$$
\lambda>(1+\kappa) m
$$

\section{Appendix C: Real Income and Employment}

(I) Real Income

We have that under the assumption that aggregate prices are normalized to one, i.e. $\mathrm{P}=\mathrm{P}^{*}=1$ a symmetric equilibrium with full employment in the export sectors in which

$$
r \equiv \int W_{i} l_{i} g(i) d i
$$

Considering wages and employment in the different types of sectors, we have for the import sectors that

$$
W^{i}=W^{r} \quad, l_{i}=0 \quad \text { for } \quad i \in I \equiv\left[\lambda^{-1},(1+\kappa)^{-1} m^{-1}[\right.
$$

for contestable import sectors

$$
\begin{aligned}
W_{i} & =a_{i}^{-1}(1+\kappa) W^{m} \quad l_{i}=A_{i}^{-1}\left(A^{*-1}(1+\kappa) W^{m}\right)^{-\theta} r \\
\text { for i } & \in C I \equiv\left[(1+\kappa)^{-1} m^{-1},(1+\kappa)^{-1}[\right.
\end{aligned}
$$


Product Market Integration, Wage Dispersion and Unemployment 25

for non-tradeable sectors

$$
W_{i}=W^{m} \quad 1_{i}=A_{i}^{-1}\left(A_{i}^{-1} W^{m}\right)^{-\theta} r \quad \text { for i } \in N T \equiv\left[(1+\kappa)^{-1},(1+\kappa) m[\right.
$$

and for the export sectors we have

$$
W_{i}=a_{i} P_{i} \quad l_{i}=1 \quad \text { for } \mathrm{i} \in E \equiv[(1+\kappa) m, \lambda] .
$$

It follows straightforwardly that

$$
\begin{aligned}
\frac{\partial r}{\partial \kappa}= & \int_{i \in C I} \frac{\partial W_{i} l_{i}}{\partial \kappa} g(i) d i+\int_{i \in N T} \frac{\partial W_{i} l_{i}}{\partial \kappa} g(i) d i+\int_{i \in E} \frac{\partial W_{i} l_{i}}{\partial \kappa} g(i) d i \\
& +W_{n} l_{n} g(n)(1+\kappa)^{-2} m^{-1}
\end{aligned}
$$

where $\mathrm{n} \equiv(1+\kappa)^{-1} m^{-1}$

$$
\begin{aligned}
\int_{i \in C I} \frac{\partial W_{i} l_{i}}{\partial \kappa} g(i) d i= & {\left[(1-\theta)(1+\kappa)^{-\theta}\left(W^{m}\right)^{1-\theta}+\left((1+\kappa) W^{m}\right)^{1-\theta} \frac{\partial r}{\partial \kappa}\right] } \\
& \int_{i \in C I} A_{i}^{-1} a_{i}\left(A^{*-1}\right)^{-\theta} g(i) d i \\
\int_{i \in N T} \frac{\partial W_{i} l_{i}}{\partial \kappa} g(i) d i= & {\left[\left(W^{m}\right)^{1-\theta} \int A_{i}^{\theta-1} g(i) d i\right] \frac{\partial r}{\partial \kappa} } \\
\int_{i \in E} \frac{\partial W_{i} l_{i}}{\partial \kappa} g(i) d i= & \int_{i \in E} a_{i} \frac{\partial P_{i}}{\partial \kappa} g(i) d i
\end{aligned}
$$

The price of exportables is determined from the equilibrium condition that domestic supply equals demand from domestic and foreign consumers

$$
A_{i}=\left(P_{i}\right)^{-\theta}\left(1+(1+\kappa)^{-\theta}\right) r
$$

Hence

$$
\frac{\partial P_{i}}{\partial \kappa}=\frac{P_{i}}{\theta}\left(\frac{1}{\left(1+(1+\kappa)^{-\theta}\right) r}\right)\left(\left(1+(1+\kappa)^{-\theta}\right) \frac{\partial r}{\partial \kappa}-\theta r(1+\kappa)^{-\theta-1}\right)
$$

Hence, it can be concluded that provided $\mathrm{g}(\mathrm{n})$ is not too large then

$$
\frac{\partial r}{\partial \kappa}<0
$$

Note for later reference that this implies that

$$
\frac{\partial P_{i}}{\partial \kappa}<0
$$


Product Market Integration, Wage Dispersion and Unemployment 26

(II) Aggregate employment

Define aggregate employment as

$$
l \equiv \int l_{i} g(i) d i
$$

hence,

$$
\begin{aligned}
\frac{\partial l}{\partial \kappa}= & \int_{i \in C I} \frac{\partial l_{i}}{\partial \kappa} g(i) d i+\int_{i \in N T} \frac{\partial l_{i}}{\partial \kappa} g(i) d i+\int_{i \in E} \frac{\partial l_{i}}{\partial \kappa} g(i) d i \\
& +l_{n} g(n)(1+\kappa)^{-2} m^{-1}
\end{aligned}
$$

where we have

$$
\begin{aligned}
& \frac{\partial l_{i}}{\partial \kappa}=A_{i}^{-1}\left(A^{*-1}(1+\kappa) W^{m}\right)^{-\theta}\left[-\theta r(1+\kappa)^{-1}+\frac{\partial r}{\partial \kappa}\right]<0 \quad \text { for } i \in C I \\
& \frac{\partial l_{i}}{\partial \kappa}=A_{i}^{-1}\left(A^{-1} W^{m}\right)^{-\theta} \frac{\partial r}{\partial \kappa}<0 \quad \text { for } i \in N T \\
& \frac{\partial l_{i}}{\partial \kappa}=0 \quad \text { for } \quad i \in E
\end{aligned}
$$

Hence, it follows that provided $\mathrm{g}(\mathrm{n})$ is not too large

$$
\frac{\partial l}{\partial \kappa}<0
$$

\section{Appendix D: Wage Dispersion}

We have that

$$
\Omega=\int\left(W_{i}-E W\right)^{2} g(i) d i
$$

where

$$
E W=\int W_{i} g(i) d i
$$

and

$$
\begin{aligned}
& W_{i}=0 \text { for } \mathrm{i} \in I \\
& W_{i}=a_{i}^{-1}(1+\kappa) W^{m} \text { for } \mathrm{i} \in I \\
& W_{i}=W^{m} \text { for } \mathrm{i} \in N T
\end{aligned}
$$


Product Market Integration, Wage Dispersion and Unemployment 27

$$
W_{i}=a_{i}^{-1} P_{i} \text { for } \mathrm{i} \in E
$$

It follows that

$$
\frac{\partial \Omega}{\partial \kappa}=2 \int\left(W_{i}-E W\right) \frac{\partial W_{i}}{\partial \kappa} g(i) d i+\left(W_{n}-E W\right) g(n)(1+\kappa)^{-2} m^{-1}
$$

Using that

$$
\begin{array}{ll}
\frac{\partial W_{i}}{\partial \kappa}=a_{i}^{-1} W^{m}>0 \quad \text { and } \quad \mathrm{W}_{i}<E W & \text { for } \mathrm{i} \in I \\
\frac{\partial W_{i}}{\partial \kappa}=0 \quad \text { for } \mathrm{i} \in N T & \\
\frac{\partial W_{i}}{\partial \kappa}=a_{i}^{-1} \frac{\partial P_{i}}{\partial \kappa}<0 \quad \text { and } \quad \mathrm{W}_{i}>E W & \text { for } \mathrm{i} \in E
\end{array}
$$

and

$$
\left(W_{n}-E W\right) g(n)(1+\kappa)^{-2} m^{-1}<0
$$

it follows that

$$
\frac{\partial \Omega}{\partial \kappa}<0
$$

\section{References}

Agell, J., 2000, On the Determinants of Labour Market Institutions: Rentsharing vs. Social Insurance, Working Paper, Uppsala University.

Andersen, T.M., N. Haldrup and J.R. Sørensen, 2000, Labour Market Implications of EU Product Market Integration, Economic Policy, 30, 107133.

Andersen, T.M. and J.R. Sørensen, 2000, Product Market Integration and Wage Formation, Journal of Economic Integration, 15, 281-293.

Borjas, G.J., and V.A. Ramey, 1985, Foreign Competition, Market Power, and Wage Inequality, Quarterly Journal of Economics, 1075-1110.

Davis, D.R., 1998, Does European Unemployment Prop Up American Wages? National Labor Markets and Global Trade, American Economic Review, 88, 478-494. 
Product Market Integration, Wage Dispersion and Unemployment 28

Dornbusch, R., Fischer, S., and P.A. Samuelson, 1977, Comparative Advantage, Trade and Payments in a Ricardian Model with a Continuum of Goods, American Economic Review, 67, 823-839.

Obstfeld, M. and K. Rogoff, 1996, Foundations of International Macroeconomics, MIT Press.

OECD, 1999, EMU-Facts, Challenges and Policies.

Flanagan, R.J., 1999, Macroeconomic Performance and Collective Bargaining: An International Perspective, Journal of Economic Literature, XXXVII, 1150-1175.

Rodrik, D., 1997, Has Globalization Gone too Far? Institute for International Economic Studies, Washington.

Slaugther, M.J., and P. Swagel, 1997, The Effects of Globalization on Wages in Advanced Economies, IMF Working Paper, 97-43. 


\section{IZA Discussion Papers}

\section{No Author(s) \\ 191 G. C. Giannelli C. Monfardini}

192 G. Brunello

193 A. Kunze

194

A. Newell

F. Pastore

195 F. Büchel

A. Mertens

196

J. S. Earle

K. Z. Sabirianova

197

G. A. Pfann

198

M. Kreyenfeld

C. K. Spiess

G. G. Wagner

199 H. Entorf

200 T. Bauer

G. S. Epstein

I. N. Gang

201 T. J. Dohmen

G. A. Pfann

202 P. Francois

J. C. van Ours

203 J. M. Abowd

F. Kramarz

D. N. Margolis

T. Philippon

G. S. Epstein

A. L. Booth

M. Francesconi

J. Frank
Titel

Area

Date

Joint Decisions on Household Membership and 5 Human Capital Accumulation of Youths: The role of expected earnings and local markets

$8 / 00$

Absolute Risk Aversion and the Returns to

5

$8 / 00$

Education

The Determination of Wages and the Gender

Wage Gap: A Survey

5

$8 / 00$

Regional Unemployment and Industrial

4

$8 / 00$

Restructuring in Poland

Overeducation, Undereducation, and the Theory

of Career Mobility

$9 / 00$

Equilibrium Wage Arrears: A Theoretical and 4

$9 / 00$

Empirical Analysis of Institutional Lock-In

Options to Quit

$9 / 00$

A Forgotten Issue: Distributional Effects of Day

$9 / 00$

Care Subsidies in Germany

$9 / 00$

Zero Illegal Migration Flows: Lessons from

Modelling the Market for Illegal Migration

What are Migration Networks?

$9 / 00$

Worker Separations in a Nonstationary Corporate 1

$9 / 00$

Environment

Gender Wage Differentials in a Competitive Labor

$9 / 00$

Market: The Household Interaction Effect

The Tail of Two Countries: Minimum Wages and 5

$9 / 00$

Employment in France and the United States

Labor Market Interactions Between Legal and

1

$10 / 00$

Illegal Immigrants

Temporary Jobs: Stepping Stones or Dead Ends? $\quad 1$

$10 / 00$ 


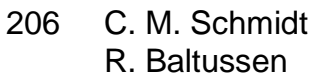

R. Sauerborn

207 C. M. Schmidt

208 J. Hartog

R. Winkelmann

209 M. Barbie

M. Hagedorn

A. Kaul

210 T. J. Dohmen

211 A. van Soest

M. Das

X. Gong

212 X. Gong

A. van Soest

P. Zhang

213 X. Gong

A. van Soest

E. Villagomez

214 X. Gong

A. van Soest

215 J. Ermisch

M. Francesconi

216 F. Büchel

217 J. Hansen

R. Wahlberg

218 C. Dustmann

A. van Soest

219 F. Kramarz

T. Philippon

220 W. A. Cornelius E. A. Marcelli
The Evaluation of Community-Based Inter-

Arbeitsmarktpolitische Maßnahmen und ihre

6

$10 / 00$

Evaluierung: eine Bestandsaufnahme

Dutch Migrants in New Zealand:

1

$10 / 00$

Did they Fare Well?

Dynamic Effciency and Pareto Optimality in a

$10 / 00$ Stochastic OLG Model with Production and Social Security

Housing, Mobility and Unemployment

$11 / 00$

A Structural Labour Supply Model with

5

$11 / 00$ Nonparametric Preferences

Sexual Bias and Household Consumption: A

Semiparametric Analysis of Engel Curves in Rural China

Mobility in the Urban Labor Market: A Panel Data 1

$11 / 00$ Analysis for Mexico

$11 / 00$

Family Structure and Female Labour Supply in

5 Mexico City

The Effect of Parents' Employment on Children's

5

$11 / 00$ Educational Attainment

The Effects of Overeducation on Productivity in

5

$11 / 00$ Germany - The Firms' Viewpoint

Occupational Gender Composition and

5

$11 / 00$

Wages in Sweden

Parametric and Semiparametric Estimation in 1

$11 / 00$ Models with Misclassified Categorical Dependent Variables

The Impact of Differential Payroll Tax Subsidies on 5

$11 / 00$ 

former Soviet Union to Israel: Who is coming when? 

of Labor Income Risk and Car Insurance in the UK 1969-95

241 W. Koeniger

Trade, Labor Market Rigidities, and GovernmentFinanced Technological Change

$01 / 01$

242 G. Faggio J. Konings

Job Creation, Job Destruction and Employment the 1990s

244 S. M. Fuess, Jr.

Pay and Productivity in a Corporatist Economy:

$01 / 01$ M. Millea

Evidence from Austria

Globalization and Human Capital Formation 

incentives Matter?

Multi-Generation Model of Immigrant Earnings: national Integration and Unemployment 